\title{
Ni mártires ni bandidos. La guerrilla del GPG en Chihuahua (1963-1965)
}

\section{Neither martyrs nor bandits. The GPG guerrilla in \\ Chihuahua (1963-1965)}

Carmen Andrea Elena Ríos*

*Licenciada en historia por la Facultad de Estudios Superiores Acatlán, Universidad Nacional Autónoma de México. Ha participado el proyecto MUSICAT del Instituto de Investigaciones Estéticas de la UNAM (2010-2011), El Centro de Documentación e Investigación de la Comunidad Askenazí de México (2011) y la Comisión de la Verdad del Estado de Guerrero (2012-2013). Forma parte del Seminario de historia de Corea en la Facultad de Ciencias Políticas y Sociales de la UNAM. Actualmente investiga sobre los movimientos guerrilleros del reino de Choson (Corea). Su tema de interés está en los movimientos guerrilleros en Chihuahua (México) y la Península Coreana. Correo electrónico andrea.elena.rios@gmail.com

https://orcid.org/0000-0003-1663-5230

Historial editorial

Recibido: 13-mayo-2018

Primera revisión: 22-mayo-2018

Segunda revisión: 29-agosto-2018

Aceptado: 06-septiembre-2018

Publicado: 31-octubre-2018 
Ni mártires ni bandidos. La guerrilla del GPG en Chihuahua (19631965)

\section{Resumen}

El escenario general que México presentaba en los años que van de 1963 a 1965 y que corresponden al cambio de sexenio de Adolfo López Mateos (1958-1964) a Gustavo Díaz Ordaz (1964-1970), era complejo en lo político, económico y social, tanto en el sector rural como en el urbano. La falta de oportunidades de trabajo en el campo y la fábrica, el rezago educativo; el empleo de cuerpos paramilitares para reprimir al pueblo; la dependencia económica hacia el imperialismo norteamericano; así como las arbitrariedades cometidas por un gobierno cuyas políticas económicas y sociales afectaron a amplios sectores de la sociedad, fueron la base fundamental que provocó el nacimiento de un movimiento guerrillero ${ }^{\mathrm{I}}$ autodenominado Grupo Popular Guerrillero (GPG), que era liderado por el profesor Arturo Gámiz García y auspiciado por la juventud de izquierda, contra el entonces gobernador Práxedes Giner Durán. ${ }^{2}$ El levantamiento bélico inició con diferentes acciones colectivas en contra del Estado (a manera de movimiento social primero y, después, como movimiento armado) culminando con el asalto al Cuartel Madera el 23 de septiembre de 1965. Después de este acontecimiento, los actores sociales fallecidos fueron considerados como "mártires". Por su parte, el gobierno, de manera particular la Dirección Federal de Seguridad (DFS) Por ello, este trabajo muestra a los guerrilleros como actores sociales que tenían la clara intención de mejorar las condiciones de vida de la sociedad y el modelo político imperante ${ }^{5}$, pero sin considerarlos 14 "mártires" ni "bandidos" sino como hombres conscientes de una realidad social y, como tal, que tuvieron aciertos y errores.

Palabras Clave: Mártires, bandidos, guerrilla, guerrillero. 
Neither martyrs nor bandits. The GPG guerrilla in Chihuahua (19631965)

\section{Abstract}

The general scenario, political, economic, rural and urban that Mexico exhibited in the years 1963 to 1965 and that corresponds to the change of sexennium from Adolfo López Mateos (1958-1964) to Gustavo Díaz Ordaz (1964-1970) was characterized by: offering few job opportunities in the countryside and in urban factories, presenting limited possibilities of access to education, repressing people with paramilitary bodies, experiencing a marked economic dependence on US imperialism and allowing arbitrary acts committed by a government whose social and economic policies affected large-scale sectors of society. This scenario was the fundamental basis that led to the birth of a self-proclaimed guerrilla movement such as Grupo Popular Guerrillero (GPG) led by Professor Arturo Gámiz García and supported by left-wing youth against the then governor Práxedes Giner Durán. The guerrilla began as a movement of collective actions against the State (first as a social movement and then as an armed movement) that culminated in the assault on the barracks of the city of Madera on September 23, 1965. After this event, the social actors who died during the assault were regarded as "martyrs". For its part, the government, in particular, the Federal Security Directorate (DFS) described them as "bandits". However, this work considers the guerrilla as a social movement whose purpose was to improve the living conditions of society and reform the prevailing political model and its actors not as "martyrs" nor "bandits" but as men with flaws and virtues, who were conscious of their social reality.

Keywords: Martyrs, bandits, guerrilla, warrior. 


\section{Introducción}

El escenario general del país en los años que van de 1963 a 1965 y que corresponden al cambio de sexenio de Adolfo López Mateos (I958-1964) a Gustavo Díaz Ordaz (1964-1970) estuvo caracterizado por una serie de conflictos de índole político, económico y social tanto en lo rural como lo urbano. La Dirección Federal de Seguridad y la milicia, organismos encargados de "proteger" la integridad de la nación, se convirtieron en grupos de intolerancia con la pretensión de castigar y vulnerar a la población. Una de las entidades que padeció con profundidad los embates de la política represiva fue Chihuahua, particularmente Ciudad Madera. ${ }^{6}$

La falta de oportunidades de trabajo en el campo y la fábrica; el rezago educativo; el empleo de cuerpos paramilitares para reprimir al pueblo; la dependencia económica hacia el imperialismo norteamericano; así como las arbitrariedades cometidas por un gobierno cuyas políticas económicas y sociales afectaron a amplios sectores de la sociedad, fueron la base que propició el nacimiento de un movimiento guerrillero autodenominado Grupo Popular Guerrillero, ${ }^{7}$ liderado por el profesor Arturo Gámiz García y auspiciado por la juventud de izquierda, en contra del entonces gobernador de Chihuahua Práxedes Giner Durán. ${ }^{8}$

La historia armada mexicana ha sido marcada por triunfos, pero también por derrotas, pues estas son enseñanzas nos hablan de hartazgo, conciencia social, valentía y debilidades de quienes formaron parte de alguna acción en contra del gobierno. Pese a ello, el GPG

16 consiguió formar, a decir de López (20I0), una organización político militar de izquierda que comenzó desde la particularidad regional con la idea de que se extendiese a toda la República Mexicana. Los antecedentes del alzamiento bélico los encontramos en el movimiento de Rubén Jaramillo (I900-I962), personaje que fue perseguido por su 
permanente lucha a favor del reparto de tierras en el estado de Morelos (López, 2016).

De la guerrilla del GPG se ha escrito en contadas ocasiones, a diferencia de movimientos como El Partido de los Pobres de Lucio Cabañas o la Liga Comunista 23 de Septiembre, que recibió ese nombre en honor al GPG y para recordar el levantamiento de Ciudad Madera, aunque pocos lo reconocen. En cuanto a la literatura referente al tema encontramos los trabajos de José Santos Valdés (profesor normalista) con su libro Madera. Razón de un martiriologio (sic), publicado en I968, y El color de las Amapas, crónica de la Guerrilla en la Sierra de Sonora de Ignacio Lagarda (2007).

En cuanto al trabajo historiográfico, se encuentra el libro intitulado Movimientos armados en México, siglo XX coordinado por Verónica Oikión y Martha Eugenia Ugarte. De los documentos que puntualizan la guerrilla del GPG con mayor extensión y precisión encontramos Historia de las organizaciones político militares de izquierda en México (López, 2000 y López, 2010) y Amargo lugar sin nombre de Hugo Esteve Díaz (20I3).

Desde la perspectiva periodística tenemos México Armado de Laura Castellanos (2007), los trabajos testimoniales El asalto al Cuartel Madera; 23 de septiembre de 1965. Testimonio de un sobreviviente (2003) de Raúl Florencio Lugo Hernández, Sueños de libertad de Francisco Ornelas Gómez (2005) y Las armas del Alba (2009) de Carlos Montemayor. ${ }^{9}$ Después de haber leído cada documento mencionado, puedo decir que el gran mérito de la guerrilla del GPG fue que proponía una alternativa que rompió con los paradigmas tradicionales de la izquierda que esperaban pacientemente que se presentaran las condiciones para una revolución. Los guerrilleros fueron los primeros en promover un movimiento de carácter marxista ${ }^{\mathrm{IO}}$ por la vía violenta. 
Metodológicamente hablando, este trabajo inicia con Los motivos del levantamiento en Chihuahua para que se entiendan las causas que incitaron el surgimiento de la guerrilla, continúa con el Activismo del GPG para hacer referencia a las actividades política del grupo guerrillero y su transición de una etapa de resistencia pacífica a movimiento armado (de activistas políticos a bandidos sociales). Se hace alusión al hecho histórico (23 de septiembre de 1965) que convirtió a los guerrilleros en Los mártires de Madera y cierra con las consideraciones finales.

A partir de ello y, tomando en cuenta la opinión de Peter Burke, quien explica que la historia desde las capas segregadas "fue concebida en su origen como la inversión de la historia desde arriba poniendo la cultura baja en el lugar de la cultura alta" (1999, p. 24); es necesario explorar nuevas perspectivas del pasado, donde sea permisible indagar la historia desde los grupos sociales subalternos y a partir de algunas interrogantes que el mismo autor cuestiona: ¿Quién es el pueblo? ¿Lo son los pobres, las clases inferiores? La respuesta que cabría en este trabajo es que el pueblo son los subalternos que se identifican con el GPG, pues ellos emergieron de ese sector (relegado por la clase dominante) y son quienes crean este ambiente popular que refieren los historiadores británicos Eric Hobsbawm y Edward P. Thompson. Aquí se retoman las ideas que maneja el primero (Hobsbawm, I983a y 1983b).

Ahora bien, se abre un paréntesis para entender la importancia de la tendencia ideológica del GPG en su carácter marxista ${ }^{\text {II }}$ (también por ser

18 la corriente historiográfica empleada en el trabajo). La doctrina marxista en su vertiente marxista- leninista tuvo gran influencia en la guerrilla del GPG donde:

El leninismo introdujo un elemento nuevo en la doctrina marxista que no estaba presente en los escritos de Marx. Este suponía que la dirección general del proceso histórico ya 
estaba definida, aunque su forma concreta estaría determinada por la acción política, saliendo así de la esfera de la libertad [Iggers, 2003, p. I33].

En torno a las diversas dimensiones que ofrece este objeto de estudio sobre el particular, Jim Sharpe considera que "se había tendido a restringir el estudio de la historia desde abajo a los episodios y movimientos en los que las masas emprenden una actividad política abierta" (citado por Burke, 2007, p. 46). El movimiento armado del GPG, por ser la primera de las guerrillas modernas mexicanas, ha convertido a sus protagonistas en mártires (para el pueblo) y bandidos (para el gobierno). Es por ello que en este artículo se muestra lo más objetivamente posible (pues debemos de recordar que en una investigación la subjetividad comienza desde que elegimos un tema $)^{\mathrm{I} 2}$ a quienes formaron el grupo guerrillero como personas que tuvieron aciertos y errores: ni mártires ni bandidos.

\section{Los motivos del levantamiento guerrillero}

Los motivos evidentes que incitaron el surgimiento del levantamiento oscilaron entre los problemas laborales en las fábricas; con la situación de los campesinos y entre los estudiantes de las normales rurales. Desde la perspectiva histórica, un movimiento armado no se origina de manera exclusiva por la pobreza ya que esta ha existido desde antes y no necesariamente es una condición que propició el alzamiento.

No es una sola variable lo que determinó su existencia. No es la miseria lo que lo produce, pues ha existido ésta (sic) durante muchos años y no ha generado necesariamente de las masas una respuesta armada. No es sólo el uso de la violencia el que lo provoca, pues a diario se cometen muchos hechos violentos 
sin que desencadenen en una respuesta insurgente [López, 20IO, p. 25].

Efectivamente, no todos los movimientos armados se producen exclusivamente a raíz de las paupérrimas condiciones de vida. Se trata de una variable de causa y efecto donde la segregación se integra de manera sistemática a la sublevación, pues los sectores sociales relegados de la sociedad han tenido múltiples derrotas y casi ningún triunfo. Quienes han levantado la bandera de lo social no supone que la idea de alzamiento sea igual para cada poblador y para los activistas que se organizan.

La primera causa que sale al paso fue la violencia gubernamental y su corrupción en aras de mantener riqueza y poder. La violencia física y psicológica fue el móvil que utilizó el gobierno para combatir a los "bandidos" y arremeter contra la población, ya que se recurre a ella para la conservación del Estado y sus instituciones. En este sentido, las prácticas violentas son parte de esta práctica de conservación.

Si en las sociedades la ley protege la vida y la propiedad, sin embargo hay quienes carecen de esta y cuya vida no está a resguardo, o bien quienes teniendo propiedad y vida pueden ser despojados de ambos sin que tal despojo constituya delito... son vidas que no merecen la posesión de bienes y ni siquiera el disfrute de la simple existencia. El Estado pero también otros particulares pueden disponer más allá de las fronteras de lo legal. [Calveiro, 2008, pp. 26-27]

20 La funcionalidad del gobierno represivo en Chihuahua se encuentra en dos posibles causas. Primero las sociales, que permitieron delimitar la extensión de las prácticas corruptas, la probabilidad que se produjeran y el grado de tolerancia hacia la ilegalidad generalizada o reducida a grupos sociales que sabían que la ley no contaba para ellos, aunado a la 
escasa vigencia de la idea de nación y la ausencia de solidaridad entre el mismo pueblo que ampliase el bienestar común. Segundo en el abuso excesivo de autoridad de los militares, la policía rural y la Dirección Federal de Seguridad.

Por lo que se puede observar, los límites entre lo permisible y lo ilegal estaban finamente delimitados pues se trataba de incluir la violencia "legal" en contra de los bandidos-sediciosos- roba vacas que, en virtud de ello permanecían apartados de la justicia social y que es lo que lleva al origen del levantamiento del GPG en contra de la sobre explotación laboral, los problemas de acaparamiento de tierras por parte de los caciques y la política de represión en contra de los estudiantes normalistas. Los obreros no gozaban de beneficios para una vida óptima, ni de medidas que garantizaran su estabilidad económica y bienestar laboral. Se violaban sus derechos con sueldos bajos que resultaban insuficientes para mantener un nivel de vida digno; generando graves problemas de subsistencia. En un tercer punto encontramos a los campesinos que estaban con el problema del cacicazgo de los Ibarra y los Vega, principalmente, familias que reafirmaba su poder mediante créditos gubernamentales y acaparamiento de tierra; aunado a esto, tenían jornadas de trabajo extenuantes con una paga miserable, viéndose obligados a quedarse en esa tierra debido a las deudas interminables que adquirían y dejaban como herencia a sus hijos y nietos.

Y, finalmente, el problema en las Escuelas Normales Rurales, que eran centros de estudio orientados más al trabajo en el campo. El normalismo dibujó en el estudiante la idea del deber ser y la enseñanza plasmada en su misión cultural con un sentimiento de orgullo y respeto. La Escuela Normal también otorgó al estudiante una visión de servicio, el carácter proteccionista, el sentido libertario, mesiánico y la 
formación de sus profesores que se configuraron en una relación de conocimiento y reconocimiento frente a la población.

Las normales rurales pronto fueron señaladas como semillero de guerrilleros por realizar acciones políticas que criticaban al gobierno estatal y nacional, ${ }^{\mathrm{I3}}$ por tanto, se implementó un plan para su desaparición, bajo la excusa que se habían desviado de su verdadero objetivo: la educación popular.

\section{El activismo político del GPG}

De las filas de las normales egresó el luchador social Arturo Gámiz (futuro líder del Grupo Popular Guerrillero) ${ }^{\mathrm{I} 4}$ quien buscó las armas como fin último. Los estudiantes se ocuparon de la acción política desde las aulas a manera de lucha social y política. En el Segundo Encuentro de la Sierra Heraclio Bernal se publicó un documento intitulado La Participación de los Estudiantes en el Movimiento Revolucionario con la clara intención de sensibilizar a los futuros maestros en los aspectos fundamentales de la vida de nuestro país y el papel que jugaban en el proceso revolucionario.

Las normales rurales con mayor activismo fueron Salaices (para varones) y Saucillo (para mujeres) que se encontraban bastante bien organizadas y con fuerte identidad y conciencia del papel que jugaban en el trabajo al lado de los grupos segregados. Otro punto en el que el trabajo pone atención es el contacto con el pueblo, donde interviene la

22 relación abajo-abajo mencionada anteriormente.

En el Primer Encuentro en la Sierra, celebrado en Cebadilla de Dolores Municipio de Madera, entre el 7 y 15 de octubre, asistieron diversos sectores marginales encabezados por los estudiantes de las Juventudes Populares del Partido Popular, las Normales Rurales de Salaices y Saucillo, el Tecnológico de Chihuahua, la Universidad de Chihuahua y 
otros centros educativos provenientes de Delicias, Camargo, Parral y Casas Grandes. Entre los guerrilleros que participaron en dicho encuentro estaban los ya mencionados Arturo Gámiz y Oscar González Eguiarte (AGN). Para explicar sus acciones bélicas, los guerrilleros decidieron llevar a cabo -en febrero de 1965- un segundo encuentro que dividieron en dos partes. La primera consta de cuatro resoluciones que hacen referencia al problema de la acumulación capitalista en México al amparo del Estado.

Las 5 resoluciones del Encuentro en la Sierra tuvieron como punto de partida el mundo colonial y semi colonial, que va desde la conquista española hasta la revolución de I9IO-I9I7, el análisis del periodo que inicia con el triunfo de la burguesía en I9I7 y el mundo en que vivimos. Estas sirvieron como argumento irrefutable del largo proceso de descomposición social emergida de la indiferencia gubernamental donde "el régimen de explotación de las minorías por las mayorías, que por doquier engendra miseria empequeñece y frustra al hombre, que impide el florecimiento pleno de su personalidad" (Segundo Encuentro en la Sierra Heraclio Bernal, 1965, s/p). Abarca hasta los años sesenta, etapa a la que se denominó Medio siglo de dictadura burguesa. En las contradicciones del capitalismo se habló sobre la proletarización, empobrecimiento de las masas, el desempleo crónico y creciente, la concentración de la producción, la formación de los monopolios y la exportación. La quinta resolución fue la proclamación del inicio del alzamiento del GPG: El único camino a seguir, las armas. Sólo faltaba tomar la decisión para dar paso a las condiciones subjetivas, (de activistas sociales a bandidos o bandoleros sociales). Así, el levantamiento bélico inició con las diferentes acciones armadas en contra del Estado, que culminaron con el asalto al Cuartel Madera el 23 de septiembre de 1965 . 


\section{De activistas políticos a bandidos sociales}

"La imagen típica de la carrera del bandolero social se vuelve bandolero porque hace algo que la opinión local no considera delictivo pero que es criminal ante los ojos del Estado o de los grupos rectores de la localidad" (Hobsbawm, I983b, p. 30). El levantamiento dio inicio cuando los guerrilleros intentaron lacerar los intereses de la empresa Bosques de Chihuahua ${ }^{15}$ con la quema de un templete en el que se presentaría el entonces candidato a la presidencia de la República, Gustavo Díaz Ordaz, y la toma de la estación de radio de la localidad. A esos acontecimientos le sucedería la muerte del hermano de José Ibarra (Florentino) a manos de Antonio Scobell Gaytán y Salomón Gaytán (Santos, I968), convirtiéndolos en bandoleros sociales pues, como dice Eric Hobsbawm "La carrera de un bandolero empieza casi siempre con algún incidente que no es grave pero le echa fuera de bando: un cargo de origen policiaco por alguna infracción y encaminada más contra su persona que a sancionar el delito" (I983 b, p. 30).

Un activista trasciende las barreras de la resistencia pacífica de una protesta -y cualquier otra forma de actividad política- a un estado armado cuando hace del bandolerismo social "poco más que una protesta endémica del campesino contra la opresión y la pobreza; un grito de venganza contra el rico y los opresores" (Hobsbawm, I983b, p. 23). Los guerrilleros dieron inicio a sus movilizaciones desde la clandestinidad. ${ }^{16}$ Víctor Orozco en Diez ensayos sobre Chihuahua, dividió la historia de la guerrilla en dos etapas: la primera que abarca

24 desde inicios de la década de los sesenta -y que puede decirse que concluye con el ataque al Cuartel Madera- y una segunda etapa en la que continuaron las luchas estudiantiles de las normales rurales y los focos guerrilleros de los sobrevivientes al asalto, que poco a poco se fueron disgregando hasta quedar erradicadas. 
Los guerrilleros se distribuyeron el estado en dos grupos: el primero en Madera, encargado de proteger la región de la sierra y que estaba encabezado por Arturo Gámiz y los hermanos Salvador y Salomón Gaytán. El segundo grupo se ubicó en la ciudad de Delicias y estaba liderado por los hermanos Pablo y Raúl Gómez Ramírez, quienes también se encargaron de coordinar con los líderes agrarios de la Unión General de Obreros y Campesinos de México (UGOCM) Álvaro Ríos y el dirigente nacional Jacinto López. El GPG pretendió seguir un movimiento masivo en contra del gobierno, pero esto implicó acciones cuerpo a cuerpo y -a su vez- un acto de resguardo de la propia vida.

La decisión fue asaltar el Cuartel de Ciudad Madera. En los primeros días de septiembre en el Barrio de Santo Niño de la ciudad de Chihuahua se llevó a cabo una reunión para planificar el asalto. La fecha se fijó, en un principio, para el i5 de septiembre. Salvador y Antonio debían sacar el armamento oculto y establecer contacto con el tercer grupo. Sin embargo el grupo que asaltó el cuartel, por esperar inútilmente a sus compañeros para que llegaran con las armas, aplazaron el ataque hasta el día 23.

\section{Los mártires de Madera}

El hecho histórico es bien conocido: un grupo de jóvenes armados con rifles, carabinas, escopetas y bombas caseras, intentaron asaltar el Cuartel de Ciudad Madera el 23 de septiembre de $1965 .{ }^{17}$ El resultado fue la muerte de ocho de los combatientes: Arturo y Emilio Gámiz, Oscar Sandoval, Rafael Martínez, Salomón Gaytán, Antonio Scobell, Miguel Quiñones y Pablo Gómez; cinco lograron escapar: Ramón Mendoza, Juan José Fernández, Guadalupe Scobell, Francisco Ornelas y Florencio Lugo Hernández. 
Después del acontecimiento, algunos opinan que los guerrilleros se asemejan a los "mártires"18 , por otro lado, tenemos la versión de la DFS que se refería a los jóvenes como gavilleros, ladrones, roba vacas y -por supuesto- bandidos. Independientemente de los calificativos que pudiesen recibir los guerrilleros de uno y otro lado, ambos términos son ambiguos. Por principio de cuentas habría que definir perfectamente el significado de cada uno de ellos.

Desde el punto de vista estrictamente religioso, un mártir es una persona que ha muerto padeciendo torturas, que es marginada $y$ perseguida por defender sus creencias, con la característica de que están resignados y destinados al sufrimiento y, por ende, a la muerte. De los actores sociales pertenecientes al GPG podemos decir que efectivamente fueron perseguidos, sin embargo, y en palabras de Florencio Lugo "En cuanto considerar mártires a los compañeros caídos en Madera... No los considero mártires porque éramos conscientes de los riesgos y peligros a que nos exponíamos" (R.F. Lugo Hernández, comunicación personal, 30 de junio de 20I5). A esta consideración se le añadiría que una cosa es estar consciente de la situación social y otra muy distinta es estar preparados para enfrentarla. Esa fue la gran desventaja del GPG.

En cuanto a llamarles bandidos, “[...]en épocas de revolución las cuadrillas (de bandoleros) se convierten en virtuales unidades de guerrilla" (Hobsbawm, I983b, p. I0). Hay que tomar en cuenta la forma en que los mismos guerrilleros se concebían pues -haciendo referencia 26 a Guerra de guerrillas- los alzados son los protectores del pueblo, una especie de "ángeles tutelares" que son presentados como una especie tutelar que llega para ayudar al pobre (Guevara, 1979). De referirnos a los alzados como mártires, su lucha sería producto de un mito creado, lo que provocaría que la gente que aún los recuerda los idealice sin tomar en cuenta su lucha desde la acción política y basados 
exclusivamente en el hecho histórico, aunado a una limitante más: El GPG tenía un proyecto de vida más no uno de muerte.

De ahí que se pueda deducir que quienes los identifican como mártires, ponen en un plano superior a los alzados que al resto de la población que también padeció la represión gubernamental (torturas, muerte y desaparición forzada) sin tomar en cuenta los motivos arriba mencionados. Aquí se considera que decirles mártires a los fallecidos del 23 de septiembre es un grave error pues convierte al hecho histórico en un mito y a los guerrilleros en sacrificados; sin tomar en cuenta las variables y consecuencias de sus actos, las cuales dieron como resultado un fallido asalto y la aniquilación de la guerrilla. Sin embargo se debe reconocer que el gran mérito del GPG fue que no esperó a que se dieran las condiciones para una revolución, ellos mismos las crearon.

Cabe señalar que el mismo Che Guevara aceptaba como equivalente el accionar de un grupo de bandoleros con los guerrilleros. Tomando como ejemplo gavillas de bandoleros que operan en una región, estas tienen todas las características del ejército guerrillero: homogeneidad, respeto al jefe, valentía, conocimiento del terreno y muchas veces, hasta cabal apreciación de la táctica a emplear (Guevara, 1979). A los delincuentes comúnmente los asociamos como bandidos cuando la intencionalidad del acto es obtener un beneficio propio; en cambio, un guerrillero lo hace en beneficio de un colectivo y con una finalidad bastante definida: solucionar los problemas de la entidad con un sentido político y social.

Por su parte, en el reporte oficial, el gobierno optó por desprestigiar el movimiento del Grupo Popular Guerrillero, minimizar su causa y la importancia de la misma. ${ }^{19}$ Sin embargo, la interpretación de Hobsbawm sobre el bandolerismo social (aplicado en la figura del guerrillero) rompe con la tradición historiográfica que lo considera como mero delincuente "un fuera de la ley, a todo participante en las 
luchas armadas contra el poder establecido, situando en un primer plano, en el campo de la investigación histórica, a movimientos sociales que los prejuicios ideológicos y sociales habían relegado al anonimato de los archivos policiacos, las páginas sensacionalistas de los periódicos, leyendas, relatos y cantos populares (López, 20I2, s/p). En este sentido, llamarlos bandidos, gavilleros y roba vacas, responde a un planteamiento político en el que las autoridades trataban de minimizar la labor emprendida por el GPG. ${ }^{20}$

\section{Consideraciones finales}

Los integrantes del Grupo Popular Guerrillero estuvieron mitificados como hombres embozados, armados y pertrechados que buscaron apoyar a las poblaciones y comunidades marginales. Estas los convirtieron en mártires y el gobierno - por su parte- en bandidos; pero dichas maneras de concebirlos no son exclusivas de este caso, sino que son adjetivaciones del momento empleadas en procesos armados de larga data que convierten al bandolero social en héroe y en bandido a la vez. Toda coyuntura muestra el azar y la contingencia, pero también tendencias estructurales de más largo plazo que es necesario investigar para explicar y comprender este tan singular momento de la historia armada mexicana y evitar estereotipar a los actores sociales.

La historia oficial mexicana, al negar el estudio sobre los grupos menos favorecidos, se encargó de convertir a las masas en el grupo olvidado donde la historia social no tiene opción para el análisis. Ello implicaría responder a un planteamiento político represivo en el que las autoridades trataban de minimizar la labor de resistencia emprendida por los guerrilleros. Así, el Estado ha convertido a la violencia extrema aplicada en contra de los grupos marginales, en tradicionales conflictos 
de clases y problemas de huelguistas obreros, campesinos y estudiantes que no tenían mayor relevancia.

Partiendo de los términos descritos en torno a la figura del Grupo Popular Guerrillero, se debe señalar que para evitar confusión y tachar de tal o cual manera a los guerrilleros, es necesario conocer las diferentes posturas, confrontarlas y sacar conjeturas propias. Los historiadores no debemos permitir que nuestro país se convierta en un pueblo sin memoria, porque eso debilita. Promover el olvido es una estrategia de las clases dominantes para vulnerar y manipular la conciencia, a través de mediaciones ideológicas encaminadas a controlar o impedir los movimientos sociales de concientización y resistencia.

Preocupa, sin embargo, que el conocimiento se construya únicamente a partir de la investigación actual, con herramientas (fuentes tradicionales) que, si bien ofrecen una imagen nítida y una narrativa coherente sobre el fenómeno, no extraen aquellos mecanismos inmersos en las profundidades de la vida cotidiana, que nos permitan conocer estos episodios en toda su complejidad. No se toman en cuenta las múltiples formas de hacer historia (mediante el cine, la música, la fotografía, el arte, la historia oral, entre otros) para investigar con mayor profundidad la guerrilla del GPG, lo que nos priva de un conocimiento más amplio sobre este levantamiento.

Por otro lado -si retomamos los conceptos de mártires y bandidos- a primera vista nos encontramos en posiciones normativas irreconciliables y en posturas políticas que afectan -inevitablemente- la toma de decisiones sobre cómo abordar el tema de la guerrilla. Pese a que al levantamiento armado se le ha estudiado desde varios puntos de vista, ya sea a través de los medios de comunicación o como resultado del encuentro entre el discurso del gobierno, la sociedad organizada y el de los propios investigadores; se ha convertido en un andamiaje de 
supuestos, medias verdades, sentido común y de conclusiones impecables. Ante este escenario, no pocas veces las investigaciones parten de axiomas equivocados y visiones diferentes que llegan a ser duramente criticadas por salirse de lo tradicional. Se considera que las investigaciones sobre la historia armada del GPG casi no dejan espacio para la reinterpretación.

Uno de los problemas que persiste en el estudio de la guerrilla del GNG radica en la forma de conceptualizar al movimiento pues, si bien es cierto que referirse a ella como una guerrilla socialista no está mal, se deben tomar en cuenta las variantes de la significación de la resistencia (pacífica y/o armada), el papel tan fundamental que jugaron los escritos marxistas en la formación académica de los guerrilleros normalistas, la historicidad contenida en las resoluciones de los Encuentros en la Sierra y la misma reinterpretación del asalto al Cuartel Madera (como en este trabajo que utilizar la historiografía y la historicidad para definir el alzamiento como la primera guerrilla marxista mexicana con cualidad de autodefensa popular). Empero, el legado que dejó el GPG sirvió de inspiración y ejemplo para los levantamientos armados que se suscitaron en nuestro país a lo largo los años sesenta, setenta y ochenta.

\section{Referencias}

Burke, P. (2007). Formas de hacer historia. Madrid, España: Alianza Universidad.

30 Calveiro, P. (2008). "Acerca de la difícil relación entre violencia y resistencia.” En López Maya, M.; Iñigo Carrera, N.; y Calveiro P. (Eds.) Luchas contrahegemónicas y cambios políticos recientes de América Latina, (pp. 23-46). Buenos Aires: CLACSO.

Castellanos, L. (2007). México Armada 1943-I98I. México: Ediciones Era. 
Chopin, J.V. (2008). La iglesia de los mártires. El Salvador: Universidad Don Bosco.

Dirección Federal de Seguridad (DFS). Catálogo Comunista, González Oscar, Exp. I00-5-3-63. H 245 LI, tarjeta I. Archivo General de la Nación [AGN], México.

Dirección Federal de Seguridad (DFS). Gonzáles Ediarte (Eguiarte) Oscar. Archivo General de la Nación [AGN], México.

Dirección Federal de Seguridad (DFS). Lugo Hernández Florencio, Legajoi/2 y I/3. Archivo General de la Nación [AGN], México.

Dirección Federal de Seguridad (DFS). Versiones Públicas, Giner Durán Práxedes, legajo 2/3, f. 57. Archivo General de la Nación [AGN], México.

Esquivel, J.L. (I2 de mayo de 20I2). La historia secreta de la dirección federal de seguridad. La "CIA mexicana". Recuperado de http://esquivelzubiri.blogspot.com/2012/05/la-historia-secreta-de-la-direccion.html

Esteve Díaz, H. (2016). Amargo Lugar sin nombre. Crónica del movimiento armado socialista en México (1960-1990). Guadalajara, Jalisco: Taller la casa del mago.

Guevara de la Serna, E. (1979). Guerra de Guerrillas. La Habana, Cuba: Universidad de la Habana.

Harnecker, M. (1972). "Capitalismo y socialismo". Cuadernos de Educación Popular: ¿Qué es el socialismo? Núm. 6. México: Universidad Autónoma de Puebla.

Hobsbawm E.J. (1983b). Rebeldes Primitivos. Estudio de las formas arcaicas de los movimientos sociales en los siglos XIX y XX. Barcelona, España: Editorial Ariel. 
Hobsbawm, E.J. (1983a). Marxismo e historia social. México: Instituto de Ciencias de la Universidad Autónoma de Puebla.

Iggers, G.G. (2002). La historiografía del siglo XX; desde la objetividad científica al desafío posmoderno. Chile: Fondo de Cultura Económica.

Lagarda, I. (2007). El color de las Amapas, crónica de la Guerrilla en la Sierra de Sonora. Hermosillo, Sonora: Universidad Tecnológica del sur de Sonora.

López Limón, A.G. (2000). Autoritarismo y cambio político; historia de las organizaciones político militares en México. (1945-1965) (Tesis de maestría). Facultad de Ciencias Políticas y Sociales de la UNAM, México.

López Limón, A.G. (2010). Historia de las organizaciones político militares de izquierda en México (I960- 1980) (Tesis doctoral). Facultad de Ciencias Políticas y Sociales de la UNAM, México.

López Limón, A.G. (2016). Vida y obra de Rubén Jaramillo. México: El Zenzontle, MIR.

López Rivas, G. (I2 de octubre de 2012) "El concepto de bandolerismo social en Eric Hobsbawm. La Jornada. Recuperado de http://www.jornada.com.mx/20I2/IO/I2/opinion/o24aIpol

Lugo Hernández, R.F. (2003). El asalto al Cuartel Madera; 23 de septiembre de 1965. Testimonio de un sobreviviente. México: Centro de derechos Humanos Viaaxkin AC/Foro permanente de la Comisión de la Verdad.

Montemayor C. (2009). Las armas del Alba. México: De Bolsillo.

32 Oikión Solano, V. y García Ugarte, M.E. (coords.) (2009). Movimientos armados en México Siglo XX. Vol. I, II y III. México: El Colegio de Michoacán/CIESAS.

Ornelas Gómez, F. (2005). Sueños de libertad. Chihuahua, México: s/ed. 
Orozco, V. (2003). Diez ensayos sobre Chihuahua. Chihuahua, México: Doble Hélice.

Romero Contreras, O. (2006). La dialéctica marxista leninista (Tesis de licenciatura). Universidad Autónoma Metropolitana, México.

Santos Valdés, J. (1968). Madera. Razón de un Martiriologio (sic). México: Editorial Laura.

Secretaría de Industria y Comercio. (1967). Anuario Estadístico de los Estados Unidos Mexicanos 1964-I965. México: Talleres Gráficos de la Nación.

Secretaría de la Defensa Nacional (SEDENA). Caja 235, No.68I, A/o3o/5 Año 1964-66. Archivo del Estado Mayor secc. Secretaría. Garantías de la 5/a Zona Militar. Rel.3I-I-76.

Segundo Encuentro en la Sierra Heraclio Bernal. (1965). Durango, México: Ediciones Línea Revolucionaria.

\footnotetext{
${ }^{\mathrm{I}}$ Un movimiento guerrillero es una forma particular mediante la cual algunos sectores subalternos intentan destruir los aspectos centrales del orden vigente, al que consideran injusto, para construir uno nuevo. Se producen cuando los sectores dominantes tienen dificultades para continuar ejerciendo su poder. Las acciones culminan con la destitución de las autoridades del viejo orden y su reemplazo por otras provenientes de los mismos grupos revolucionarios que emprenden transformaciones centrales en la sociedad a través de profundos cambios económicos, políticos y sociales.

${ }^{2}$ Práxedes Giner Durán (I893-1978) fue combatiente durante el Gobierno de Porfirio Díaz y luchando también con Venustiano Carranza. "Fue comandante de la 27/a Zona militar de Acapulco Guerrero, comandante de la 5/a Zona Militar... su carrera militar es de aspecto revolucionario..." Desempeñó el cargo de gobernador del estado de Chihuahua de I962 a I968 (Archivo General de la Nación [AGN]).

${ }^{3}$ La Dirección Federal de Seguridad fue creada durante el mandato de Miguel Alemán y fue concebida como una policía de élite encargada de proteger al presidente. "El primer director de la DFS sería el Teniente Coronel Marcelino Inurreta de la Fuente,
} 
un ex veterano de la Revolución. El subdirector de la Agencia, sería el Mayor Manuel Mayoral García, quien controlaba el tráfico de mariguana en todo el país; el Jefe de Control de Agentes, Juan Ramón Gurrola; los Jefes de Grupo serían Alvaro Basail de la Vía y Ernesto Moncada canalizó, también a dos tenientes y ocho subtenientes recién egresados del Heroico Colegio Militar, así como una veintena de policías" (Esquivel, 20I2). La DFS contaba con un director federal de seguridad, un comité coordinador conformado por el jefe de cada departamento y jefe de cada sección y en la generalidad por la división operativa que -a su vez- contaba con una Secretaría de Estado y organismos descentralizados, organización de obreros, organización estudiantes y profesionales, organización de campesinos, organización de iniciativa privada, partidos de derecha y clero, organización de partidos de izquierda, control de institutos culturales, cámaras y partidos políticos. De la misma manera tenía un departamento jurídico, el departamento de asuntos internos encargado de vigilar a sus elementos y el departamento de seguridad; contaba con una sección de investigaciones diversas, una sección de apoyo compuesta por egresados de la academia de la DFS pero que no tenían especialización y eran desplazados al interior de la República, la sección de seguridad interna, sección de transmisiones; así como agentes de seguridad a funcionarios, los departamentos de inteligencia que vigilaba a los gobiernos extranjeros -particularmente a los latinoamericanos- y un área de contrainteligencia que se especializaba en vigilar a los extranjeros que llegaban a México (asilados políticos particularmente) y control a extranjero. Tenía el departamento de operaciones clandestinas, los agentes del área clasificada y el departamento antropométrico encargado de analizar en "su individualidad" a los subversivos, a quienes "clasificaban psicológicamente" y hacían estimaciones de los diversos grupos guerrilleros jerarquizando el grado de peligrosidad y contrarrestar el avance de sus movimientos [considero que estos últimos fueron los "torturadores" y la referencia es mi interpretación sobre la DFS con base en los documentos que consulté dentro de la Galería i en el AGN entre 20II y 20I4. En ese momento no contaban con permiso para digitalizar documentos, por tanto, no es una referencia específica. También pongo en claro que la información archivística empleada -salvo versiones públicas- ya no cuenta con permiso a préstamo en sala, sin embargo, todo el material que localicé, puede ser consultado en la Universidad Autónoma de Chihuahua -Dr. Jesús Adolfo Trujillo- el Periódico Madera -Jaime Laguna Berber-, el 34 acervo del Museo Casa de la Memoria Indómita -Raúl Florencio Lugo Hernández y Teresa Scobell Gaytán].

${ }^{4}$ Un mártir se define aquella persona que es criticada, marginada e incluso perseguida por sus ideas o creencias. Es una persona que ha muerto, especialmente padeciendo torturas o con gran sufrimiento. Se trata de la memoria de los perseguidos y el sentido de la liberación y el ejercicio de la libertad y sacramentalidad del martirio pues desde tiempos de San Agustín, la iglesia camina entre las persecuciones del mundo y los consuelos de Dios. Para la Iglesia, entonces, no es opcional el realizar su misión en pobreza y persecución pues, es una condición que le viene impuesta desde su misma 
naturaleza histórica (Chopin, 2008). El bandido como tal es un asaltante que delinque para su propio beneficio, sin embargo, en el caso del Grupo Popular Guerrillero y partiendo de lo dicho por Eric Hobsbawm el bandido social no delinque por beneficio personal, el bandolerismo social es una nueva forma de protesta social que el autor conceptualiza como una manera primitiva de protesta social organizada y sitúa este fenómeno en condiciones rurales. El bandolerismo social se presenta como una forma de resistir a los ricos, a los opresores extranjeros, a las fuerzas que de una u otra forma destruyen el orden considerado tradicional en condiciones extraordinariamente violentas (López, 20I2).

${ }^{5}$ La idea era cambiar el sistema político capitalista, que tiene vertientes políticas y sociales, en el que el capital predomina sobre el trabajo. Los medios de producción (dinero, tierra, fábricas, máquinas, etc.) están en manos de una clase social propietaria (la burguesía), en tanto que los trabajadores (proletarios) están desprovistos de cualquier pertenencia, lo que los obliga a vender lo único que poseen para sobrevivir (su fuerza de trabajo) percibiendo a cambio un salario. El valor del trabajo realizado -por el contrario- una parte del mismo (la plusvalía) se la apropiaba el capitalista, dando lugar a una acumulación de capital. El socialismo, por el contrario, surgió como respuesta al nacimiento y desarrollo del capitalismo moderno. Fue la base de una serie de afirmaciones utópicas; sin embargo, casi todos estos primeros experimentos comunistas fracasaron; ya que fueron realizados a pequeña escala, implican la cooperación voluntaria y todos los miembros de las comunidades creadas participaban en el proceso de gobierno (Harnecker, 1972).

${ }^{6}$ Chihuahua está situado al norte de México y tiene una extensión de $247087 \mathrm{~km}^{2}$, es el estado más grande del país y se encuentra entre la altiplanicie y la Sierra Madre Occidental. Es característica su extensa riqueza forestal y ganadera. Entre 1964 y 1965 contaba con 7932 localidades, I6 ciudades, I3 villas, I73 pueblos, 99 congregaciones, I45 haciendas y fincas, 319 ejidos, 5478 ranchos y i 065 rancherías. Sus límites son con los Estados Unidos de América por el norte y noreste; Coahuila por el este; Durango por el sur; Sonora al oeste y Sinaloa hacia el suroeste. La cantidad de ríos es menor si tomamos en cuenta la enorme extensión de tierra que presenta. Cuenta con tres vertientes de agua: la primera hacia el Golfo de México, la segunda hacia el Océano Pacífico y, finalmente, la interior. La Secretaría de Industria y Comercio, al realizar su censo de los años I964 y I965, registró un índice poblacional total de 1226793 personas. El número total de habitantes era de I 447515 con una densidad poblacional del $5.20 \%$ y un incremento de 220822 pobladores" (Secretaría de Industria y Comercio, 1967). En I960 Chihuahua estaba dividido en doce distritos electorales entre los que destacan Hidalgo del Parral, Cuauhtémoc, Cd. Juárez. Cd. Camargo, Cd. Jiménez, Cd. Guerrero, Batopilas, Guadalupe y Calvo, y Uruachi. Ciudad Madera se encuentra aproximadamente a 276 kilómetros de la ciudad de Chihuahua y está enclavada en la Sierra Madre Occidental. El nombre del municipio tiene su origen en un aserradero maderero y una estación de tren para el embarque de la madera que se estableció en I906. Hacia I965 Madera contaba con un aproximado de I2 mil habitantes. Sus límites 
son al norte con el municipio de Casas Grandes; al este con Zaragoza, Gómez Farías y Temósachi; al suroeste con los municipios de Náori Chico, Bacadéjuachi y Sahuaripa del estado de Sonora. Alcanza una altitud de 2 iIo metros sobre el nivel del mar (Santos, 1968 y AGN).

${ }^{7}$ Un guerrillero es un luchador social que busca cambiar el sistema de gobierno autoritario y represivo a un modelo socialista y evitar el avance imperialista en su país (en este caso, México). De aquí en adelante utilizaré de forma indistinta Grupo Popular Guerrillero y GPG.

${ }^{8}$ Para ver más sobre el tema puede revisarse a López (2000) y (2010).

${ }^{9}$ Entre los principales guerrilleros del movimiento de Madera encontramos a su líder Arturo Gámiz García, quien nació el 28 de febrero de 1940 en Súchil, Durango. Cursó y aprobó el sexto grado en la Escuela Primaria Federal "José Ma. Morelos y Pavón" de La Villa. En 1955 se inscribió en la Escuela Secundaria Federal No. 4 del Distrito Federal, y al año siguiente empezó a participar en la Juventud Popular del PP. En I957 fue Secretario General de la Sociedad de Alumnos de la citada escuela y formó parte del Comité de Huelga en apoyo del movimiento realizado por el Instituto Politécnico Nacional. Emilio Gámiz García -hermano de Arturo- nació en la ciudad de Puebla, el I9 de mayo de 1945 y también fue estudiante normalista. Pablo Gómez Ramírez nació en Saucillo, al sur del estado de Chihuahua, y se dedicó a organizar a los campesinos sin tierra. Discutió y promovió medidas para evitar que a los ejidatarios se les privara de sus derechos. Miguel Quiñonez Pedroza nació en San Bernardo, al norte de Durango, el 6 de octubre de 1943 y murió el 23 de septiembre de I965. Sus padres fueron Miguel Quiñonez y María del Refugio Pedroza. Estudió su primaria en San Bernardo bajo la dirección del profesor Alfredo N. Herrera, de quien recibió apoyo para ingresar a la Escuela Normal Rural de Salaices, Chih. Los demás guerrilleros que participaron en el asalto al Cuartel Madera, el 23 de septiembre de 1965, fueron Oscar Sandoval Salinas, Rafael Martínez Valdivia, Francisco Ornelas Gómez (sobreviviente en la actualidad), Juan José Fernández Adame, Ramón Mendoza Torres, Guadalupe Scobell Gaytán, Salomón Gaytán Aguirre, Florencio Lugo Hernández (sobreviviente en la actualidad) y Antonio Scobell Gaytán. Junto con ellos Oscar González Eguiarte y Salvador Gaytán Aguirre (Santos, 1968).

$36{ }^{\text {Io }}$ A la guerrilla del GPG se le ha señalado como moderna, contemporánea o socialista, sin embargo nadie se ha tomado la molestia de revisar la influencia política e ideológica marxista para identificarla como guerrilla marxista, como lo propone este trabajo.

${ }^{\text {II }}$ Para ver más sobre el tema puede revisarse Romero (2006).

${ }^{\mathrm{I} 2}$ También debemos tomar en cuenta que no podemos conocer la historia tal como sucedió. El historiador hace una construcción del pasado, lo analiza y lo interpreta pero ello no significa que su pensamiento sea totalmente objetivo, pues está 
influenciado por alguna corriente historiográfica y -en general- por los propios intereses del historiador.

${ }^{13}$ Inicialmente las Escuelas Normales fueron concebidas para complementar el desarrollo agrícola. Cuando el gobierno abandonó el proyecto de la reforma agraria se condenó a los campesinos a una vida miserable, de tal suerte que los problemas de la gente se fueron complicando. En este contexto cambió totalmente el tipo de liderazgo de los futuros maestros, quienes protestaron y se rebelaron en contra del gobierno (algunos de ellos futuros guerrilleros como Miguel Quiñones Pedroza y Rafael Martínez Valdivia).

${ }^{\mathrm{I}}$ Para ver más sobre el tema puede revisarse La Participación de los Estudiantes en el Movimiento Revolucionario en: http://madera1965.com.mx

${ }^{15}$ La empresa Bosques de Chihuahua controlaba la riqueza forestal de la región, dejando tras de sí miseria y tierras arrasadas. Las propiedades fueron adquiridas por la gran burguesía latifundista, ganadera, minera y maderera (Santos, 1968).

${ }^{16}$ "Con fecha 29 de febrero de 1964 destruyeron un puente; el 5 de marzo del mismo año asesinaron al señor Florentino Ibarra, el I2 de abril siguiente incendiaron una casa y la estación de Radio al servicio de la misma; el is de julio del año próximo pasado atacaron por sorpresa a un grupo de Agentes de la Policía del Estado, en Dolores, Chih., quitándoles las armas, privándolos de su libertad por varios días y lesionando a dos de ellos; durante el presente año atacaron a un pelotón de Soldados del $52^{\circ}$ Batallón de Infantería en la Sierra de Madera, hiriendo a tres de ello" (Valdés, 1968, p. I24).

${ }^{17}$ En el levantamiento armado no participaron todos los guerrilleros como Salvador Gaytán y Óscar González Eguiarte porque no consiguieron alcanzar a sus compañeros y llegar el día señalado, sin embargo, su trabajo fue muy significativo durante el levantamiento del Grupo Popular Guerrillero e -incluso- después de la desaparición del mismo.

${ }^{18}$ José Luis Alonso Vargas ex guerrillero de "Los guajiros" siempre ha expresado que los integrantes del GPG fueron los "Mártires de Madera". Se considera que esa opinión se basa en una visión romántica del levantamiento más que en un pensamiento crítico sobre los errores que tuvo esa guerrilla.

19 "Se ha puesto en marcha una campaña agresiva, falsaria, en contra del movimiento armado... Alterar la historia para desacreditar al movimiento revolucionario, es iniciativa de los representantes del sistema; la finalidad es restarle méritos y que no sea ejemplo a seguir para las nuevas generaciones" (R.F. Lugo Hernández, comunicación personal, 23 de septiembre de 2013). 
${ }^{20}$ Entonces, como dice Hobsbawm "el bandolerismo social es una forma de protesta social organizada cuando el oprimido no ha adquirido métodos más eficaces que la agitación social" (López, 2012, s/p.).

Este artículo se publica bajo una licencia de Creative Commons Reconocimiento-NoComercial 4.0 Internacional, y puede ser usados gratuitamente para fines no comerciales, dando los créditos a los autores y a la revista.

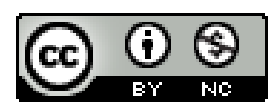

